\title{
The Effect of Market Regimes on Style Allocation
}

Manuel Ammann

Michael Verhofen

Working Paper Series in Finance

Paper No. 20 


\title{
The Effect of Market Regimes on Style Allocation
}

\author{
Manuel Ammann and Michael Verhofen*
}

\begin{abstract}
We analyse time-varying risk premia and the implications for portfolio choice. Using Markov Chain Monte Carlo (MCMC) methods, we estimate a multivariate regime-switching model for the Carhart (1997) four-factor model. We find two clearly separable regimes with different mean returns, volatilities and correlations. In the High-Variance Regime, only value stocks deliver a good performance, whereas in the Low-Variance Regime, the market portfolio and momentum stocks promise high returns. Regime-switching induces investors to change their portfolio style over time depending on the investment horizon, the risk aversion, and the prevailing regime. Value investing seems to be a rational strategy in the High-Variance Regime, momentum investing in the Low-Variance Regime. An empirical out-of-sample backtest indicates that this switching strategy can be profitable, but the overall forecasting ability for the regime-switching model seems to be weak compared to the iid model.
\end{abstract}

*Manuel Ammann (manuel.ammann@unisg.ch) is professor of finance at the Swiss Institute of Banking and Finance, University of St. Gallen, Switzerland, and Michael Verhofen (verhofen@gmail.com) is visiting scholar at the Haas School of Business, University of California at Berkeley, United States of America. We thank two referees, Bernd Brommundt, Thorsten Hens, Alexander Ising, Stephan Kessler, Axel Kind, Angelika Noll, Ralf Seiz, Stephan Süss, Evert Wipplinger, Rico von Wyss, and Andreas Zingg for valuable comments. We acknowledge helpful comments from the participants of the conference of the German Finance Association in Augsburg in October 2005 and of the 9th conference of the Swiss Society for Financial Market Research in Zürich in April 2006. We acknowledge financial support from the Swiss National Science Foundation (SNF). 
JEL: G11, G12, G14

Keywords: Regime Switching, Style Investing, Markov Chain Monte Carlo, Tactical Asset Allocation 


\section{Introduction}

Equity style classes such as value stocks, growth stocks, small and large caps are popular from an academic and practical perspective. From an academic perspective, there is strong evidence that a portfolio of value stocks, small stocks and momentum stocks has historically earned a return above the return predicted by the CAPM, as mentioned by Rosenberg, Reid \& Lanstein (1985), Banz (1981), and Jegadeesh \& Titman (1993). To explain this finding, two different approaches have been suggested, a rational, multifactor asset pricing approach and an irrational approach based on anomalies. From a practitioner's perspective, style factors are usually used to determine asset allocation, according to Kao \& Shumaker (1999).

Overall, style decisions have a large impact on the performance of a portfolio. Carhart (1997), for example, finds that cross-sectional differences of mutual fund performance can almost completely be explained by style factors. Moreover, style premia seem to be, at least partially, predictable (Grünenfelder (1999)). For example, Fama \& French (1998) document that the value premium (HML) and the size premium (SMB) might be related to economic growth. Similarly, Kao \& Shumaker (1999) and Lucas, Dijk \& Kloek (2002) show how style rotation based on macroeconomic variables can be implemented.

Time-varying expected returns and, therefore, at least partially predictable returns can be regarded as a generally accepted fact in finance, as mentioned by Cochrane (1999). As shown by Evans (1994), time-varying expected returns are due to two sources of variation, variation in factor loadings and variation in risk premia. A number of approaches have been suggested to model the dynamics of factor loadings, of expected returns, or of the joint dynamics, such as Evans (1994), Ferson \& Harvey (1999), Ghysels (1998).

Our goal is to analyze time-varying risk premia and the implications for asset allocation. To quantify the effect, we use a regime-switching model that enables us to allow for time-varying mean returns, volatilities and correlations. More specifically, our contribution consists of two main parts.

First, we formulate a data-generating process for risk premia that al- 
lows for asymmetric means, volatility, and correlation. A regime-switching model reproduces asymmetric patterns, whereas standard models such as multivariate normal or multivariate GARCH models do not. Therefore, our approach of modelling time-varying risk premia is fundamentally different from traditional approaches such as Evans (1994), where time variation is captured by a linear function of state variables. In the approach pursued here, expected returns, volatilities, and correlations vary with the regime rather than with state variables. To our knowledge, this extension of regime-switching models to multi-factor asset pricing models has not been performed up to now. Existing applications focus on one-factor models (for an comprehensive overview we refer to Kim \& Nelson (1999)). Overall, our setup is comparable to the approach proposed by Ang \& Bekaert (2002), although the focus of our analysis is different. Whereas Ang \& Bekaert (2002) focus on time-varying world market integration, i.e., on time-varying correlations, we focus on time-varying means, volatilities, and correlations of risk premia for different style classes.

The empirical results provide interesting new insights into the time series behavior of the market risk premium (MRP), the size premium (SMB), the value premium (HML), and the momentum premium (UMD). We find two clearly separable regimes with different means, volatilities, and correlations. Regime 1, occurring approximately $25 \%$ of the sample period, is characterized by high volatility, low returns for MRP and UMD, medium returns for $\mathrm{SMB}$, and high returns for HML. In contrast, Regime 2 is characterized by low volatility, high returns for the market portfolio and momentum stocks, and small returns for small caps and value stocks. Regime 2 occurs approximately $75 \%$ of the sample period and is more stable than Regime 1, i.e., the likelihood of switching from Regime 2 to Regime 1 is smaller than vice versa. To check for the stability of the model, we use a rolling scheme. The rolling scheme validates previous findings, i.e., in Regime 1 value stocks deliver the highest return, in Regime 2, the market portfolio and momentum stocks. Overall, estimated parameters are reasonably stable for Regime 2 and exhibit larger variation in Regime 1 than in Regime 2.

Second, we analyze the implications for asset allocation from a strategic 
and tactical point of view. From a strategic perspective, we numerically solve and develop intuition on the style allocation problem in the presence of regime switches for investors with constant relative risk aversion (CRRA) preferences. From a tactical perspective, we test empirically tactical asset allocation strategies based on the regime-switching model. Most existing approaches have focussed on switching within one style class (e.g. switching between growth and value stocks). In contrast, we show that switching between different style classes can be a promising strategy. In particular, value investing during the High-Variance Regime and momentum investing during the Low-Variance Regime has historically earned a superior performance. An out-of-sample analysis indicates that the findings are relatively robust, i.e., the results are similar in different subperiods, and the trading strategies seem to remain profitable after accounting for transaction costs. To our knowledge, this is the first paper analyzing the use of regime-switching models for tactical style allocation.

The outline of this paper is as follows. We start in Section 2 by giving a literature overview on regime-switching models, existing applications in finance, and style investing. Then, we continue by formulating the general asset allocation problem in Section 3, show how to numerically solve the problem with regime-switching, and show how to estimate parameters for regime-switching models. In Section 4 , we present our empirical results and discuss our results in the light of existing literature. Section 5 concludes.

\section{Literature Overview}

This paper is related to three branches of the existing literature. The first branch is the issue of parameter estimation for regime-switching models. The classical reference for regime-switching models is Hamilton (1989). For an extensive overview concerning the econometrics issues of regimeswitching models and an overview about empirical evidence, we refer to Kim \& Nelson (1999). One of the first papers in financial econometrics that estimates time-varying integration of single countries to the world market is Bekaert \& Harvey (1995). 
The second branch of literature, portfolio choice and regime-switching, analyzes the effects of regime-switching on asset allocation. Overall, the main findings are that regime switching induces a change in the asset allocation depending on the investment horizon and depending on the current regime. One of the main references is Ang \& Bekaert (2002). In their paper, they analyze dynamic asset allocation with regime shifts in an international context. Recent contributions include Graflund \& Nilsson (2003), Bauer, Haerden \& Molenaar (2003), Ang \& Bekaert (2004), and Guidolin \& Timmermann (2005).

Finally, the third branch analyses the issue of style investing, i.e., the asset allocation in comparison to specific style factors such as momentum stocks, growth and value stocks, and small and large caps. Barberis \& Shleifer (2003) study asset prices in an economy where some investors categorize risky assets into different styles and move funds among these styles depending on their relative performance. From an empirical point of view, the contributions by Kao \& Shumaker (1999), Arshanapalli, Ouville \& Nel-

son (2004), and Cooper, Gutierrez \& Hameed (2004) are related to this paper because they also analyze time variation in returns for different investment styles.

\subsection{Regime-Switching Models in Finance}

Hamilton (1994) and Kim \& Nelson (1999) give an overview about the econometrics of state-space models with regime-switching. From an econometric point of view, the main problem in estimating regime-switching models is the unobservability of the prevailing regime. Two different approaches have been suggested: a classical maximum likelihood based on filters such as the Hamilton filter or on the expectation maximization algorithm and a Bayesian approach based on numerical Bayesian methods such as the Gibbs sampler and Markov Chain Monte Carlo methods. Kim \& Nelson (1999) provide an overview of possible applications to finance. Depending on the purpose of a particular analysis, regimes are usually separated by differences in the mean, volatility, or different behavior of volatility such as different factor loadings for an ARCH model. Objects of the analysis are usually uni- 
variate time series such as a representative stock index or an interest rate. In a multivariate setting, Bekaert \& Harvey (1995), for example, estimate a multivariate regime-switching model.

\subsection{Portfolio Choice and Regime Switching}

A number of authors analyze the implications of regime-switching in portfolio selection. Ang \& Bekaert (2002) analyze international asset allocation with regime shifts. The starting point of their paper are time-varying correlations between different equity markets. In bad times correlations and volatilities increase in comparison to good times and, therefore, the investment opportunity set is stochastic. In the empirical part, they assume a two state model with Markov switching and constant transition probabilities. For parameter estimation, they use a Bayesian procedure similar to Hamilton (1989) and Gray (1996). Overall, there are always relatively large benefits of international diversification, although the optimality of the home-biased portfolios cannot always be rejected statistically. The costs of ignoring regime switching are very high if the investor is allowed to switch to a cash position. If the investment universe is limited to equities, costs of ignorance are lower. With respect to hedging demands, they find that intertemporal hedging demands under regime-switching are economically negligible and statistically insignificant. Similar, Ang \& Bekaert (2004) find that for a global all-equity portfolio, the regime-switching strategy dominates static strategies in an out-of-sample test. In a persistent high-volatility market, the model tells the investors to switch primarily to cash.

\subsection{Style Investing}

According to Kao \& Shumaker (1999), "style" is broadly defined as any system of classification by market segment that have distinguishing characteristics. Given the large number of possible criteria which can be used to separate investments strategies, academics and practitioners have developed sets of common characteristics of factors to measure style. Beta, size, value, growth, quality, momentum, leverage, and even sectors are commonly used 
criteria to differential investment styles. Most frequently used for classification in academic literature is the Fama \& French (1993) three-factor model (market risk, size, value vs. growth) and the momentum factor by Carhart (1997). With respect to the equity premium a vast number of studies addressing unconditional and conditional aspects have been published, such as Evans (1994), Cochrane (1999), Fama \& French (2002), and Rey (2005).

The importance of momentum for stock returns has first been documented by Jegadeesh \& Titman (1993) and is still an active research area. Overall, most studies, such as Jegadeesh \& Titman (2001) and Korajczyk \& Sadka (2004), indicate that momentum trading is a robust strategy, even after trading costs. According to George \& Hwang (2004), momentum investing is closely related to the 52-week-high investing and is mainly due to industry effects, according to Moskowitz \& Grinblatt (1999). While the size effect and the value premium seem to predict future economic growth, as argued by Liew \& Vassalou (2000), this is not the case for the momentum premium, as noted by Griffin, Ji \& Martin (2003). As shown by Badrinath \& Wahal (2004), momentum investing is a very popular investment strategy followed by institutional investors.

Similar to momentum stocks, value stocks have historically shown an abnormal performance in almost any country, as noted by Fama \& French (1998). Cohen, Polk \& Vuolteenaho (2003) show that the expected return on value stocks depends on the cross-sectional dispersion of the market-to-book ratios. The value spread has shown strong seasonalities, according to Kao \& Shumaker (1999). Value stocks have a higher return in the first quarter and growth stocks in the fourth quarter. Moreover, analysts are very likely to underestimate earnings of value companies, as Doukas, Kim \& Pantzalias (2002) point out. With respect to the size effect originally discovered by Banz (1981), new evidence by Berk (1997) and Knez \& Ready (1997) casts some doubt on the robustness of the size premium.

Style rotation and equity style timing has recently been addressed by a number of authors. Kao \& Shumaker (1999) analyze the opportunities for equity style timing. Based on the Fama \& French (1993) factors, using recursive partitioning (regression and classification trees) and macroeconomic 
factors (term spread, real bond yield, corporate credit spread, high-yield spread, estimated GDP growth, earnings-yield gap, CPI), they try to predict future differences in style returns. They find that timing strategies in the US market based on asset class and size have historically provided more opportunity for outperformance than a timing strategy based on value and growth. An extended analysis shows that return differences between value and growth stocks have a straightforward, intuitive basis. The key insight, from the point of view of this article, is that there is strong evidence of cyclical time variation of style factors and that the variation seems to be related to macroeconomic factors. Similarly, Arshanapalli et al. (2004) address the question whether size, value, and momentum are related to recession risk. Their main finding is that an increase in the conditional variance for HML and UMD coincides with a higher recession probability within a time horizon of six months.

Levis \& Liodakis (1999) investigate the opportunity for style rotation in the United Kingdom. They implement and test a style rotation model based on OLS regressions and a Logit model. As independent variables, they use macroeconomic factors and valuation ratios such as inflation, short-term interest rate, term spread, exchange rate, market return, and dividend yield spreads. Similarly, Lucas et al. (2002) analyze different models for style rotation in the US market and find that business cycle oriented strategies deliver a better performance than pure statistical approaches.

\section{Style Investing with Changes in Regimes}

In this section, we describe the general portfolio choice problem and the parameter estimation.

\subsection{Portfolio Choice}

The general asset allocation problem can be stated as follows. A buyand-hold investor facing at time $t$ a $T$-month horizon and an investment opportunity set consisting of $N$ assets maximizes his expected end of period utility over terminal wealth $U\left(W_{T}\right)$. Formally, 


$$
\max _{\alpha_{t}} \mathbb{E}_{t}\left[U\left(W_{T}\right)\right]
$$

where $\alpha_{t}$ denotes the vector of portfolio weights at time $t$ which must sum up to one. Next periods wealth, $W_{t+1}$, is given by $W_{t+1}=R_{t+1}\left(\alpha_{t}\right) W_{t}$. The gross return on the portfolio, $R_{t+1}\left(\alpha_{t}\right)$, is

$$
R_{t+1}\left(\alpha_{t}\right)=\sum_{j=1}^{N} \exp \left(y_{t+1}^{j}\right) \alpha_{t}^{j}
$$

where $y_{t+1}^{j}$ is the logarithmic return on asset $j$ from time $t$ to $t+1$ and $a_{t}^{j}$ is the proportion of the $j$ th asset in the investor's portfolio at time $t$. We use CRRA utility

$$
U\left(W_{T}\right)=\frac{W_{T}^{1-\gamma}}{1-\gamma},
$$

with $\gamma$ the investor's coefficient of risk aversion. The CRRA utility function is chosen because it can be regarded as the standard benchmark and the results can be compared to other findings.

We concentrate on the investment problem of a US investor and ignore intermediate consumption and dynamic asset allocation. The investment decision is taken at time 0 for the whole investment horizon. In this paper, we do not address the general market equilibrium, so the investor is not necessarily the representative agent. We also do not consider the asset allocation faced by non-US investors.

The buy-and-hold investor chooses at time $t$ the portfolio weights $\alpha_{t}^{*}$ maximizing his utility:

$$
\alpha_{t}^{*}=\arg \max _{\alpha_{t}} \mathbb{E}_{t}\left[\frac{W_{T}^{1-\gamma}}{1-\gamma}\right] .
$$

Up to now, no specific data generating process for the asset returns $y$ has been assumed and therefore, the setup is fairly general. Samuelson (1969) shows that if the returns are iid and under CRRA utility, portfolio weights are constant. Therefore, it this special case, the multiperiod solution is 
identical to the myopic solution. If returns are not iid, a hedging component might arise protecting the investor's against unfavorable changes in the investment opportunity set, as shown by Merton (1971).

We introduce $K$ different regimes $S$ into the data generating process. The return in a specific period $y_{t}$ depends on the regime $S_{t}$ prevailing at that time. The regimes $S_{t}$ follow a Markov Chain where the transition probability of going from regime $i$ at time $t$ to regime $j$ at time $t+1$ is denoted by $p_{i j, t}=p\left(S_{t+1}=j \mid S_{t}=i\right) . f\left(y_{t+1} \mid S_{t+1}\right)$ denotes the probability density function of $y_{t+1}$ conditional on regime $S_{t+1}$. In our model, $f\left(y_{t+1} \mid S_{t+1}\right)$ is a multivariate normal distribution and transition probabilities are constant. Therefore, being conditional on the regime in the previous period, $S_{t}$, the distribution of the return in period $t+1, y_{t+1}$, is a mixture of normals. The probability density function of $y_{t+1}$ conditional on $S_{t}, g\left(y_{t+1} \mid S_{t}\right)$, is given by

$$
g\left(y_{t+1} \mid S_{t}=i\right)=\sum_{j=1}^{K} p_{i j, t} \cdot f\left(y_{t+1} \mid S_{t+1}=j\right) .
$$

To compute optimal portfolio weights, we use standard numerical integration algorithms, i.e., Gaussian quadrature.

\subsection{Parameter Estimation}

A major difficulty in drawing inferences from Markov switching models is that some parameters of the model are dependent on an unobservable state variable that is an outcome of an unobserved discrete-time, discrete-space Markov process. Two different methods for parameter estimation are, in general, applicable, maximum-likelihood based approaches and Bayesian approaches using Markov Chain Monte Carlo methods such as Gibbs sampling. As noted by Kim \& Nelson (1999), in Bayesian analysis, both the parameters and the Markov-switching variable, are treated as random variables.

The model we use in this paper assumes that mean returns and their covariance matrices switch with regime. Formally, 


$$
\begin{aligned}
y_{t} & =\mu_{S_{t}}+e_{t} \\
e_{t} & \sim M V N\left(0, \Sigma_{S_{t}}\right) \\
\mu_{S_{t}} & =\mu_{1}\left(1-\left(S_{t}-1\right)\right)+\mu_{2}\left(S_{t}-1\right) \\
\Sigma_{S_{t}} & =\Sigma_{2}\left(1-\left(S_{t}-1\right)\right)+\Sigma_{2}\left(S_{t}-1\right)
\end{aligned}
$$

where $y_{t}=\left[\begin{array}{llll}M R P_{t} & S M B_{t} H M L_{t} & U M D_{t}\end{array}\right]^{\prime}$ is the vector of risk premia and $t$ is the time index. $M R P$ denotes the market risk premium, $S M B$ the size premium, $H M L$ the value premium and $U M D$ the momentum premium. $S_{t}$ denotes the state at time $t$ where $S_{t}=1$ correspondents to regime 1 and $S_{t}=2$ to regime 2. $\mu_{S_{t}}$ is the state dependent mean and $\Sigma_{S_{t}}$ the state dependent covariance matrix. $e$ is the error term assumed to be multivariate normally distributed, denoted by $M V N$, with an expected value of 0 and state-dependent covariance matrix $\Sigma_{S_{t}}$. $S_{t}$ evolves according to a two-state, first-order Markov-switching process with the following transition probabilities:

$$
\begin{aligned}
& p\left(S_{t}=1 \mid S_{t-1}=1\right)=p_{11} \\
& p\left(S_{t}=2 \mid S_{t-1}=2\right)=p_{22}
\end{aligned} .
$$

A key to the Bayesian approach is that along with $S_{t}, t=1,2, \ldots, T$, the model's unknown parameters, $\mu_{1}, \mu_{2}, \Sigma_{1}, \Sigma_{2}, p_{11}, p_{22}$, are treated as random variables. For Bayesian inference about these $T+6$ variables, we need to derive the joint posterior density, $g\left(\tilde{S}_{T}, \mu_{1}, \mu_{2}, \Sigma_{1}, \Sigma_{2}, p_{11}, p_{22} \mid \tilde{y}_{T}\right)$, where $\tilde{S}_{T}=\left[\begin{array}{llll}S_{1} & S_{2} & \ldots & S_{T}\end{array}\right]^{\prime}$ are the states of the system at any point in time, and $\tilde{y}_{T}=\left[\begin{array}{llll}y_{1} & y_{2} & \ldots & y_{T}\end{array}\right]^{\prime}$ are the data. As shown by Kim \& Nelson (1999), the joint posterior can be written as

$$
\begin{aligned}
g\left(\tilde{S}_{T}, \mu_{1}, \mu_{2}, \Sigma_{1}, \Sigma_{2}, p_{11}, p_{22} \mid \tilde{y}_{T}\right)= & g\left(\mu_{1}, \mu_{2}, \Sigma_{1}, \Sigma_{2} \mid \tilde{y}_{T}, \tilde{S}_{T}\right) \cdot \\
& g\left(p_{11}, p_{22} \mid \tilde{S}_{T}\right) \cdot g\left(\tilde{S}_{T} \mid \tilde{y}_{T}\right)
\end{aligned}
$$


where $g($.$) denotes a density. Therefore, using Markov Chain Monte$ Carlo methods such as Gibbs sampling, parameters can be estimated by repeating the following three steps until convergence has been reached:

Step 1 : Generate each $S_{t}$ from $g\left(S_{t} \mid \tilde{S}_{\neq t}, \mu_{1}, \mu_{2}, \Sigma_{1}, \Sigma_{2}, p_{11}, p_{22}, \tilde{y}_{T}\right)$ for $t=1,2, \ldots, T$

Step 2 : Generate the transition probabilities, $p_{11}$ and $p_{22}$, from $g\left(p_{11}, p_{22} \mid \tilde{S}_{T}\right)$

Step 3 : Generate $\mu_{1}, \mu_{2}, \Sigma_{1}, \Sigma_{2}$ from $g\left(\mu_{1}, \mu_{2}, \Sigma_{1}, \Sigma_{2} \mid \tilde{S}_{T}, \tilde{y}_{T}\right)$

The first step, generating $\tilde{S}_{T}$, can be written, as shown by Kim \& Nelson (1999), as

$$
g\left(S_{t} \mid \tilde{S}_{\neq t}, \mu_{1}, \mu_{2}, \Sigma_{1}, \Sigma_{2}, p_{11}, p_{22}, \tilde{y}_{T}\right) \propto g\left(S_{t} \mid S_{t-1}\right) \cdot g\left(y_{t} \mid S_{t}\right) \cdot g\left(S_{t+1} \mid S_{t}\right)
$$

where $g\left(S_{t} \mid S_{t-1}\right)$ and $g\left(S_{t+1} \mid S_{t}\right)$ are given by the transition probabilities, and $g\left(y_{t} \mid S_{t}\right) \sim M V N\left(\mu_{S_{t}}, \Sigma_{S_{t}}\right)$. $\propto$ denotes proportionality.

The second step, the generation of transition probabilities, is usually parameterized as follows. As prior for the transition probabilities a Beta distribution can be used

$$
\begin{aligned}
& p_{11} \sim \operatorname{Beta}\left(u_{11}, u_{21}\right) \\
& p_{11} \sim \operatorname{Beta}\left(u_{12}, u_{22}\right)
\end{aligned}
$$

where for a variable $X \sim \operatorname{Beta}(\alpha, \beta)$ with $\alpha, \beta>0$, the density of the Beta distribution is given by

$$
p(x)=\left\{\begin{array}{c}
\frac{\Gamma(\alpha+\beta)}{\Gamma(\alpha) \Gamma(\beta)} x^{\alpha-1}(1-x)^{\beta-1} \text { for } x \in(0,1) \\
0 \text { otherwise }
\end{array} .\right.
$$

$\Gamma$ (.) denotes the gamma function. The likelihood for the transition probabilities is given by

$$
L\left(p_{11}, p_{22} \mid \tilde{S}_{T}\right)=p_{11}^{n_{11}} \cdot\left(1-p_{11}\right)^{n_{12}} \cdot p_{22}^{n_{22}} \cdot\left(1-p_{22}\right)^{n_{21}},
$$

where $n_{i j}$ refers to the number of transitions from state $i$ to $j$ which can be 
easily counted for given $\tilde{S}_{T}=\left[\begin{array}{lll}S_{1} & S_{2} \ldots S_{T}\end{array}\right]$.

The third step, the generation of $\mu_{1}, \mu_{2}, \Sigma_{1}, \Sigma_{2}$, is pursued as follows. We impose univariate priors for each element of $\mu_{S_{t}}$ in each state

$$
\mu_{S_{t}}^{k} \sim N\left({ }_{p} \mu_{S_{t}, p}^{k} \sigma_{S_{t}}^{k}\right)
$$

where $\mu_{S_{t}}^{k}$ correspondents to the $k$ th element of $\mu_{S_{t}},{ }_{p} \mu_{S_{t}}^{k}$ the prior estimate for the mean of $\mu_{S_{t}}^{k}$ and ${ }_{p} \sigma_{S_{t}}^{k}$ the prior confidence in this estimate. As prior for $\Sigma_{S_{t}}$ we assume an Inverse-Wishart $I W$ distribution

$$
\Sigma_{S_{t}} \sim I W(v, Q)
$$

where for a $q \times q$ matrix $X$ the density of the Inverse-Wishart is proportional to

$$
p(X) \propto|Q|^{(v-q-1) / 2}|X|^{-v / 2} \exp \left(-\frac{1}{2} \operatorname{tr}\left(X^{-1} Q\right)\right) .
$$

$v$ is the degrees of freedom of the Inverse-Wishart, $Q$ the prior precision matrix, |.| denotes the determinate and $\operatorname{tr}($.$) the trace. The likelihood is a$ multivariate normal-distribution, $y_{t} \mid s_{t} \sim M V N\left(\mu_{S_{t}} \mid \Sigma_{S_{t}}\right)$.

The implementation follows the approach described in Congdon (2003). For the second step, the generation of transition probabilities, a reparameterization as described in Congdon (2003) has been used. The prior parameters have been set as follows: ${ }_{p} \mu_{S_{t}}^{k}=0$ and ${ }_{p} \sigma_{S_{t}}^{k}=1000^{0.5}$ for all $k$ and all states, $v=4$, and $Q$ is the identity matrix. It is important to stress that this parameterization incorporates no material prior information into statistical analysis. To ensure proper implementation, a Monte Carlo study has been performed to verify that the approach is able to recover the underlying data generating process correctly. Moreover, convergence of the MCMC sampler was ensured.

\subsection{Out-of-Sample Validity}

We assess the out-of-sample validity of the regime-switching model by using a number of different criteria. The one-step-ahead expected return under 
regime switching is a weighted average of the returns in Regime 1 and Regime 2 where the weights are given by the transition probabilities conditional on the prevailing state at time $t$,

$$
\mathbb{E}\left(y_{t+1}\right)=p\left(S_{t+1}=1 \mid S_{t}=i\right) \cdot \mu_{1}+p\left(S_{t+1}=2 \mid S_{t}=i\right) \cdot \mu_{2} .
$$

The one-step-ahead average root-mean-squared error $R M S E$ is given by

$$
R M S E=\left(\frac{1}{T-1} \sum_{t=1}^{T-1}\left(y_{t+1}-\mathbb{E}\left(y_{t+1}\right)\right)^{2}\right)^{0.5} .
$$

For a good external validity, smaller $R M S E$ are preferred.

As a second measure, we compute the Pearson coefficient of correlation between the forecasted return $\mathbb{E}\left(y_{t+1}\right)$ and the actual $y_{t+1}$ realization. The closer the coefficient to 1 , the better the forecasting ability of the model.

As a third measure, we regress the realizations for each risk factor $i$ on forecasted returns

$$
y_{t+1}^{i}=b_{0}+b_{1} \cdot \mathbb{E}\left(y_{t+1}^{i}\right) .
$$

Under accurate forecasts, we expect $b_{0}=0$ and $b_{1}=1$.

\section{Results}

In this section, we present the results of the analysis. After some descriptive statistics, we turn to the estimated parameters for the different regimes and analyze the stability of parameters. Then, we address the implications for portfolio choice.

\subsection{Data}

For the analysis, we use the common risk factors as introduced by Fama \& French (1993) and Carhart (1997). The data for the market portfolio 
(MRP), the high-minus-low (HML) factor, the small-minus-big (SMB) factor, the momentum factor (UMD) and the risk-free rate $(\mathrm{RF})$ is from the Fama and French data library. The sample period starts in January 1927 and ends in December 2004.

The HML and SMB factors are constructed using six value-weighted portfolios formed on size and book-to-market. These portfolios are the intersections of two portfolios formed on size and three formed on the ratio of book-to-market equity. The break point for dividing stocks between large and small is the median value of the market capitalization on the New York Stock Exchange at mid-year. The book-to-market equity ratios are based on those prevailing at the end of the previous year. The break points are the 30 th and the 70th percentiles. The SMB (small minus big) is created by subtracting the average return on the three large portfolios from the average return on the three small portfolios: $\mathrm{SMB}=1 / 3^{*}$ (Small Value + Small Neutral + Small Growth $)-1 / 3^{*}($ Big Value + Big Neutral + Big Growth). HML (high minus low) is created by subtracting the average return on the two growth portfolios from the two value portfolios: HML = $1 / 2 *($ Small Value + Big Value $)-1 / 2 *($ Small Growth + Big Growth $)$. The momentum portfolio UMD (up minus down) is derived from the six valueweighted portfolios formed on size and past performance during months t-2 through t-12. The portfolios are formed monthly and are the intersections of the size portfolios and the past performance portfolios. The monthly past performance portfolios breakpoints are the 30th and the 70th percentiles. UMD is calculated as the average return of the two high past performance portfolios minus the average return on the two low past return portfolios: $\mathrm{UMD}=1 / 2^{*}($ Small High + Big High $)-1 / 2^{*}($ Small Low + Big Low $)$.

Table 1 displays the descriptive statistics for the data used. The mean monthly return for the market risk was $0.65 \%$ with a standard deviation of $5.50 \%$; for the momentum premium, $0.75 \%$ per month with a volatility of $4.73 \%$. In contrast, the returns for SMB and HML have been less volatile $(3.38 \%$ and $3.57 \%)$, but also the average return was much lower $(0.18 \%$ and $0.48 \%$ ). The average risk-free rate (RF) was $0.305 \%$ per month.

From the viewpoint of this paper, it is important to note that the Jarque- 


\section{Table 1: Descriptive analysis}

The table displays the descriptive statistics for the data used in this analysis. The data are from the Fama and French data library. The sample starts in January 1927, ends in December 2004, and has monthly frequency. The momentum premium (UMD) showed the highest average return, closely followed by the market risk premium (MRP).

\begin{tabular}{lrrrrr}
\hline & MRP & SMB & HML & UMD & RF \\
\hline Mean & 0.647 & 0.184 & 0.481 & 0.751 & 0.305 \\
Median & 0.980 & 0.025 & 0.240 & 0.935 & 0.270 \\
Maximum & 38.180 & 38.040 & 35.350 & 18.380 & 1.350 \\
Minimum & -29.030 & -21.490 & -11.480 & -50.920 & -0.060 \\
Standard deviation & 5.489 & 3.375 & 3.574 & 4.731 & 0.257 \\
Skewness & 0.213 & 1.600 & 2.037 & -2.997 & 0.999 \\
Kurtosis & 10.627 & 23.897 & 17.635 & 30.861 & 4.112 \\
Observations & 936.000 & 936.000 & 936.000 & 936.000 & 936.000 \\
\hline Percentile (10\%) & -5.308 & -3.359 & -3.140 & -3.457 & 0.020 \\
Percentile (25\%) & -2.165 & -1.590 & -1.350 & -0.805 & 0.090 \\
Percentile (75\%) & 3.780 & 1.845 & 1.840 & 2.930 & 0.450 \\
Percentile (90\%) & 6.028 & 3.598 & 4.138 & 4.926 & 0.640 \\
Jarque-Bera test for normality & 2262.207 & 17346.256 & 8955.209 & 31527.381 & 202.813 \\
Jarque-Bera test (p-value) & 0.000 & 0.000 & 0.000 & 0.000 & 0.000 \\
\hline
\end{tabular}

Bera test indicates that all risk factors are not normally distributed. Since regime-switching models account for non-normality by using a mixture-ofnormals approach, they deliver a more accurate way of modelling the dynamics and the distribution of the factors than models using only one normal distribution.

\subsection{Regimes in Style Premia}

Table 2 displays the estimated parameters with and without regime-switching. Overall, our analysis shows two clearly separated regimes. In Regime 1, mean expected returns are low for the market risk (MRP), for the size effect (SMB), and for momentum factor (UMD). Only value stocks (HML) show high returns. Since all risk factors are very volatile, we refer to Regime 1 as the High-Variance Regime. In contrast, in Regime 2, market risk and momentum stocks have a high return while small stocks and value stocks have a low return. Since variance is for all risk factors much smaller than 
in Regime 1, we refer to Regime 2 as the Low-Variance Regime. The estimated parameter for the unconditional model without regime-switching are between the estimated parameters for Regime 1 and Regime 2.

Over the whole sample, the High-Variance Regime occurred approximately $25.2 \%$ of the time (235 out of 936 months). Consequently, the Low-Variance Regime occurred approximately $74.8 \%$ of the time (700 out of 936 months). Beside the different frequency of occurrence, the transition probabilities are very different for both regimes. While the Low-Variance Regimes shows a high degree of persistence, the High-Variance Regime is relative unstable. Periods of uncertainty seem to disappear relatively fast and periods of certainty seem to be rather stable. In particular, the LowVariance Regime has a probability of $91 \%$ of persistence. If we are in a particular month in a Low-Variance Regime, there is a $91 \%$ chance that the next month will also be in the Low-Variance Regime. Consequently, there is $9 \%$ chance that the next month is in the High-Variance Regime. In contrast, the probability of staying in the same class is with $72 \%$ much lower for the High-Variance Regime. There is a $28 \%$ chance of switching back to the Low-Variance Regime.

Mean returns, volatility, and correlations between the risk factors are statistically different between the two regimes except for the mean for SMB. Table 2 shows the results from a t-test for difference in means and volatilities and the results from a Box-M test (see e.g. Box (1949), Tang (1995), and Rey (2000)) for equivalence of the correlation matrices. In Regime 1, the excess return on the market portfolio is $0.4 \%$ per annum. Similarly, momentum stocks pay a small negative return of $-1.27 \%$ and small stocks pay a slightly higher return of $3.09 \%$, although it is not statistically different from 0 . Only value stocks offer a high return of $15.16 \%$. In comparison to the unconditional model (without regime-switching), only value stocks offer a higher return. However, the picture is different in Regime 2. Both market risk and momentum stocks offer a high return of $10.2 \%$ and $12.4 \%$ p.a., respectively. Value stocks pay, in contrast to Regime 1, a low return of $2.6 \%$. Small stocks pay in both regimes a fairly low rate of return, $3.1 \%$ in Regime 1 and $1.9 \%$ on Regime 2 . 
Volatility is approximately 10 percentage points higher in Regime 1 than in the unconditional model for each risk factor. In comparison to Regime 2, volatility in Regime 1 is about 2.6 to 3.8 times higher. In particular, for MRP, the volatility increases by a factor of 2.6 from $12.0 \%$ p.a. to $31.8 \%$ p.a., for SMB by a factor of 2.7 from $7.3 \%$ to $19.7 \%$, for HML by a factor of 3 from $7.1 \%$ to $21.3 \%$, and for UMD by 3.8 from $7.8 \%$ to $29.7 \%$.

Beside mean returns and volatilities, correlations are also affected. In general, Regime 1 is characterized by high correlations and Regime 2 by low correlations. This finding is an indication that in highly volatile markets, correlations increase and vice versa. In Regime 1, all correlations are, on a $5 \%$ level, statistically different from 0 . While the momentum factor is strongly negatively correlated with all other risk factors, all other factors (MRP, SMB, HML) exhibit positive correlations. In Regime 2, only two significant correlations can be found, between MRP and SMB and between MRP and UMD.

Figure 1 displays the estimated probability of being in the Low-Variance Regime. Shaded areas show NBER recessions in the sample period. The time period between 1928 and 1943 is characterized by a dominance of the High-Variance Regime, i.e., Regime 1, and rare regime switches. Between 1943 and 1969, the development was rather smooth. We estimate that the financial markets have been in Regime 2 most of the time, except for four short switches in 1949, 1957, 1962, and 1966. Starting in 1969, financial markets faced a period of instability lasting until 1991, characterized by frequent switches to Regime 1. Between 1991 and 1997, risk premia became again less volatile. This period of relative stability ended by 1997. By the end of 2004, the analysis indicates a Low-Variance Regime.

As shown in Table 2, there seems to be a relation between estimated regimes and NBER recessions. The unconditional probability is $25.16 \%$ for Regime 1 and $74.84 \%$ for Regime 2. Conditional on a NBER recession, the probability of Regime 1 increases to 45.45, and conditional on a NBER boom, the probability for Regime 1 decreases to $20.29 \%$. We use the Kolmogorov-Smirnov test to determine if the conditional probabilities are drawn from the same underlying population and the null hypothesis can 
be rejected at any reasonable level of significance. We conclude that the general economic condition also affects financial markets.

The robustness of the results against alternative specifications has been tested extensively. Overall, the results are robust against alternative specifications of prior distributions and of the likelihood. For example, if the prior matrix $Q$ for the Inverted-Wishart is changed from the identity matrix to 0.001 times the identity matrix, i.e., a even more uninformative setting, the results are robust. Moreover, it is straightforward to drop the assumption of a multivariate normal distribution of risk premia and to use a multivariate t-distribution, which is more robust against outliers. For example, if we include the degrees of freedom of the multivariate t-distribution as an unknown parameter and estimate this parameter jointly with the whole regime-switching model, the data show that a multivariate t-distribution with a very low degree of freedom might be suitable, i.e., the tails are fat.

\subsection{External Validity}

In this section, we analyze parameter stability by using a splitted sample and a rolling procedure.

Table 3 show the results from a splitted sample. The sample was splitted at the middle of the sample period, in December 1965. In Regime 1, mean returns for the size premium (SMB) and the value premium (HML) are higher for the first sample than for the second sample $(10.65 \%$ vs. $3.13 \%$ for SMB, $17.16 \%$ vs. $11.81 \%$ for HML) and lower for the market risk premium (MRP) and the momentum premium (UMD) (-0.14\% vs. $2.03 \%$ for MRP, $-2.36 \%$ vs. $4.79 \%$ for UMD). In Regime 2, MRP was higher for the first sample (13.30\% vs. $7.06 \%)$, and SMB, HML, and UMD (0.38\% vs. $4.51 \%$ for SMB, $2.40 \%$ vs. $2.66 \%$ for HML, $11.18 \%$ vs. $12.83 \%$ for UMD) were higher in the second sample. While estimated volatilities in Regime 2 are of comparable magnitude, volatilities in Regime 1 are higher in the first sample than in the second sample. This finding is due to the very volatile period during the great depression around 1930. Transition probabilities are comparable between samples, but Regime 2 is more persistent in the first sample (93\% vs. $86 \%$ ) than in the second sample. Mean returns 
are not statistically significant between regimes in the first sample. In the second sample, mean returns for SMB and HML are statistically different while MRP and UMD are not. Between the first and second sample, mean returns are not statistically different in Regime 1 except for the size premium. In Regime 2, mean returns are statistically different except for the value premium. 


\section{Table 2: Estimated parameters with and without regime- switching}

The table shows the estimated parameters for the model without regimeswitching and with regime-switching. Mean returns and volatility have been annualized. Regime 1 is characterized by high volatility and a low return for the market risk (MRP), for small stocks (SMB) and for momentum stocks (UMD) whereas value stocks (HML) show a high return. In Regime 2, volatility is rather small, and the return for the market portfolio (MRP) and momentum stocks (UMD) are high, whereas small stocks (SMB) and value stocks (HML) stocks display a low return. * denotes a value significant on the $95 \%$ level and ${ }^{* *}$ a value significant on the $99 \%$ level. Standard errors are in parenthesis.

\begin{tabular}{|c|c|c|c|c|}
\hline Unconditional & MRP & SMB & $\mathrm{HML}$ & UMD \\
\hline Mean & $7.77^{* *}(2.17)$ & $2.21(1.33)$ & $5.77^{* *}(1.41)$ & $9.00^{* *}(1.87)$ \\
\hline Volatility & $19.03^{* *}(0.44)$ & $11.70^{* *}(0.27)$ & $12.38^{* *}(0.29)$ & $16.39^{* *}(0.38)$ \\
\hline Correlation MRP & 1 & & & \\
\hline Correlation SMB & $0.32 * *(0.03)$ & 1 & & \\
\hline Correlation HML & $0.18 * *(0.03)$ & $0.08 *(0.03)$ & 1 & \\
\hline Correlation UMD & $-0.34 * *(0.03)$ & $-0.22 * *(0.03)$ & $-0.38^{* *}(0.03)$ & 1 \\
\hline \multicolumn{5}{|l|}{ Regime 1} \\
\hline Mean & $0.40(7.48)$ & $3.09(4.64)$ & $15.16^{*}(5.09)$ & $-1.27(7.04)$ \\
\hline Volatility & $31.80 * *(1.69)$ & $19.67^{* *}(1.04)$ & $21.25^{* *}(1.11)$ & $29.72 * *(1.61)$ \\
\hline Correlation MRP & 1 & & & \\
\hline Correlation SMB & $0.37 * *(0.06)$ & 1 & & \\
\hline Correlation HML & $0.29^{* *}(0.06)$ & $0.14^{*}(0.06)$ & 1 & \\
\hline Correlation UMD & $-0.50 * *(0.05)$ & $-0.28^{* *}(0.06)$ & $-0.46^{* *}(0.05)$ & 1 \\
\hline \multicolumn{5}{|l|}{ Regime 2} \\
\hline Mean & $10.22 * *(1.70)$ & $1.92(1.05)$ & $2.62 *(1.07)$ & $12.44^{* *}(1.14)$ \\
\hline Volatility & $12.01 * *(0.38)$ & $7.33^{* *}(0.25)$ & $7.13^{* *}(0.28)$ & $7.78^{* *}(0.31)$ \\
\hline Correlation MRP & 1 & & & \\
\hline Correlation SMB & $0.20 * *(0.04)$ & 1 & & \\
\hline Correlation HML & $-0.07(0.05)$ & $-0.07(0.04)$ & 1 & \\
\hline Correlation UMD & $0.15 * *(0.05)$ & $-0.01(0.05)$ & $-0.03(0.05)$ & 1 \\
\hline Number of states in & & in $\%$ & NBER recession & NBER boom \\
\hline Regime 1 & $235.50(16.77)$ & $25.16 \%$ & $45.45 \%$ & $20.29 \%$ \\
\hline Regime 2 & $700.50(16.77)$ & $74.84 \%$ & $54.55 \%$ & $79.71 \%$ \\
\hline Transition matrix & $\mathrm{P}(\ldots, 1)$ & $\mathrm{P}(\ldots, 2)$ & & \\
\hline $\mathrm{P}(1, \ldots)$ & $0.72(0.05)$ & $0.28(0.05)$ & & \\
\hline $\mathrm{P}(2, \ldots)$ & $0.09(0.02)$ & $0.91(0.02)$ & & \\
\hline \multicolumn{5}{|l|}{ Statistical tests } \\
\hline T-test for means & $2.17^{*}$ & 0.33 & $3.12^{* *}$ & $2.33^{*}$ \\
\hline T-test for volatility & $15.11^{* *}$ & $15.62^{* *}$ & $17.01^{* *}$ & $16.88^{* *}$ \\
\hline Box-M F-value & $131.60^{* *}$ & & & \\
\hline Box-M p-value & 0.0000 & & & \\
\hline
\end{tabular}



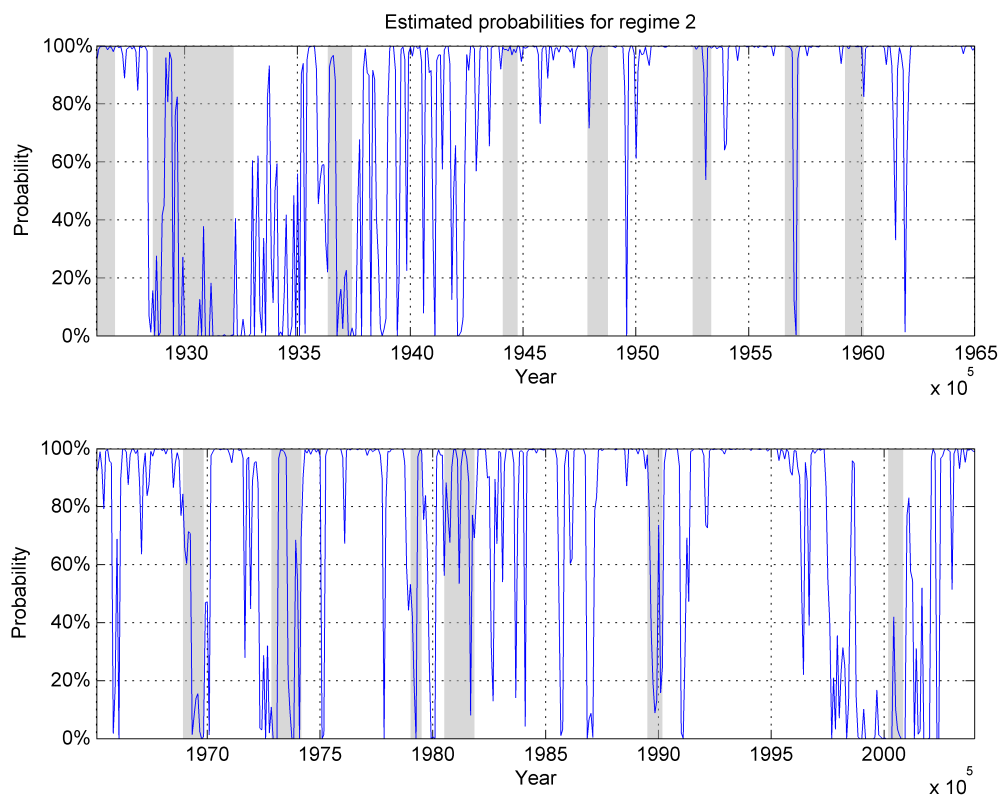

Figure 1: Estimated probabilities for Regime 2

The figure shows the estimated probabilities for Regime 2. The shaded areas show NBER recessions. We refer to Regime 2 as the Low-Variance Regime and to Regime 1 as the High-Variance Regime. In the sample period, in Regime 1, the mean return for the market risk factor (MRP), the smallsize factor (SMB) and the momentum factor (UMD) were statistically not different from 0, whereas the return on value stocks (HML) was high. In Regime 2, the market risk factor and the momentum factor showed a high return, whereas the return on the remaining two risk factors (SMB and HML) was close to 0 . In the sample period, the High-Variance Regime occured approximately $25 \%$ of the time and the Low-Variance Regime $75 \%$ of the time. 


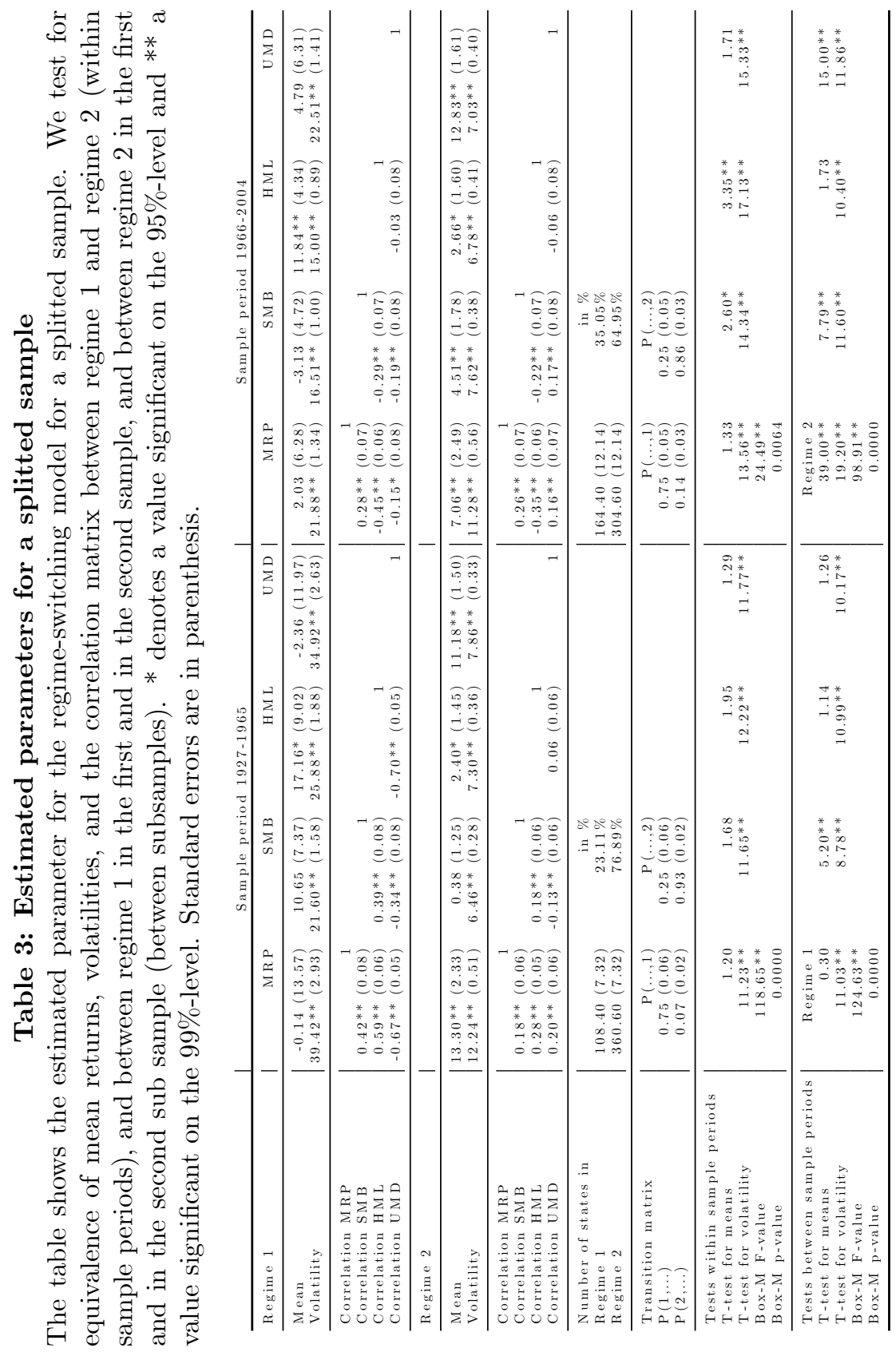


Figure 2 shows the estimated parameters based on a rolling scheme. The figure shows the estimated risk premia in \% per month for each of the four risk factors and the transition probabilities. The rolling scheme has a window size of 360 observations (30 years).

The market risk premium (MRP) shows considerable variation over time in Regime 1, the High-Variance Regime, and a more stable behavior in Regime 2. In Regime 1, MRP varies between $-0.1 \%$ and $2.3 \%$ whereas in Regime 2, MRP varies between $1.1 \%$ and $0.4 \%$. For the rolling sample from 1934 to 1963,1939 to 1968 , and 1971 to 2000, MRP was higher in Regime 1 than in Regime 2, but for the remaining time MRP was lower in Regime 1 than in Regime 2. For Regime 2, the rolling scheme shows a slight downward trend of MRP.

In Regime 1, the size premium shows a strong downward trend from a positive value of around $1 \%$ to a low of about $-0.3 \%$. During market turmoils small stocks changed their behavior. While in the early sample, small stocks delivered a high performance if the market was volatile, in the late sample, large caps delivered a high performance if the market was volatile. Regime 2, the Low-Variance Regime, shows roughly the reverse pattern. The premium on small stocks increased slightly during the sample period from about $0.0 \%$ at the early sample to about $0.3 \%$ at the end of the sample.

The value premium (HML) is in Regime 1, the High-Variance Regime, always higher than Regime 2 . The difference of the value premium in Regime 1 and Regime 2 fluctuates over time with an average of about $0.9 \%$ per month, a minimum of $0.3 \%$ per month and a maximum of $2.4 \%$ per month.

In Regime 1, the momentum premium is, in general, lower than in Regime 2. The momentum premium fluctuates in Regime 1 considerable over time. Before 1970, the average difference of momentum premia in Regime 1 and Regime 2 was about 1.2\%. Between 1970 and 1985, this difference disappeared and re-emerged by 1985 .

Transition probabilities show for Regime 1 a higher degree of instability than for Regime 2. For Regime 1, the probability of staying in the same regime declined from $72 \%$ to $50 \%$, and then suddenly jumped up to value 
between $85 \%$ and $90 \%$. This findings is due to the exclusion of the sample until 1940 because the time between 1927 and 1940 was characterized by frequent regime switches. For Regime 2, the probability of remaining in Regime 2 fluctuated between $70 \%$ and $93 \%$.

\subsection{Univariate Regime Switching}

In this section, we allow for univariate regime-switching. In the previous section, we assumed that the switching for all risk factors is governed by one Hidden Markov Model. In this section, we present the results with independent regime-switching, i.e., the evolution of each single risk factor is governed by a separate Markov process. Overall, the results are very similar to the previous findings.

Table 4 shows the estimated parameters for the model with univariate regime-switching. As previously, Regime 1 is the High-Variance Regime and Regime 2 the Low-Variance Regime. In Regime 1, small and value stocks show a strong positive return whereas the return on the market portfolio and for momentum stocks is negative. In contrast, in Regime 2, the return on the market portfolio is positive with $11.42 \%$ and for momentum stocks with $10.78 \%$. Small stocks and value stocks show a return of $1.26 \%$ and $3.11 \%$, respectively. Overall, this results are similar for the univariate and for the multivariate regime-switching approach.

During the sample period, the analysis shows that the High-Variance Regime occurred about $10.68 \%$ of the time for HML and $18.70 \%$ for SMB. The transition probabilities show a higher degree of persistence for Regime 2 than for Regime 1. While for Regime 2 the probabilities of remaining in the current regime are between 0.97 and 0.98 for all risk factors, for Regime 1 , the transition probabilities are lower with values between 0.71 and 0.89 .

Figure 3 shows the estimated probabilities for Regime 2 for the sample period. Overall, there are periods where the risk factors switch jointly and periods of independent switching. For example, during the great depression in the 1930s, MRP, SMB, and UMD apparently switched to Regime 1, while value stocks still remained in Regime 2. During the internet bubble around 2000, small stocks and momentum stocks switched to Regime 1 while value 
stocks remained in Regime 2 most of the time.

\subsection{Asset Allocation under Regime Switching}

In this section, we turn to the question how regimes affect asset allocation.

Figure 4 displays the results for an investor with a degree of relative risk aversion (RRA) of 3. The results show that an investor with an investment horizon of 3 months should allocate $36.50 \%$ to the SMB portfolio in Regime 1 and $36.09 \%$ in Regime 2. Similarly, the investor should overallocate the HML portfolio in Regime 1. The optimal allocation to HML is $37.16 \%$ in Regime 1 and $35.31 \%$ in Regime 2. Consequently, the momentum portfolio UMD should be underallocated in Regime 1 . The optimization indicates an optimal allocation of $26.33 \%$ to UMD in Regime 1 and $28.59 \%$ in Regime 2. The allocation to the market portfolio MRP is not shown because under the given assumptions, i.e., the portfolio selection problem outlined in Equations (1) to (5) and estimated parameters, optimal allocation is zero. Using historical returns as input data in a regime-switching portfolio optimization model, Figure 4 shows that the investor only selects between style classes and takes no market risk, except for the very low degree of market risk in the long-short portfolios SMB, HML, and UMD. Overall, the results are qualitatively similar for different degrees of risk aversion and therefore, Figure 4 has representative character.

The time horizon effect in Figure 4 is due to uncertainty about the prevailing regime at a future time. For example, conditional on Regime 1, a switch back to Regime 2 becomes likely due to the transition probabilities after a period of 3 months. The allocation before month 3 is mainly affected by risk and returns in Regime 1 and the allocation after month 3 is mainly affected by risk and returns in Regime 2 .

A comparison of the allocation in Regime 1 and Regime 2 stresses the importance of rebalancing. If stock markets are volatile, investors should overallocate value stocks and underallocate momentum stocks and small stocks. For a one year investment horizon, investors should increase their value stock holdings in Regime 1 by about $11 \%$ and reduces momentum positions by $7 \%$ and small stocks by $4 \%$. 
Table 5 shows the optimal asset allocation strategies for different degrees of risk aversion and maturities. A very risk-averse investor with a degree of relative risk aversion of 7 should allocate between $4.62 \%$ (for an investment horizon of 48 months) and $15.46 \%$ (for an investment horizon of 3 months) more to value stocks in Regime 1 than in Regime 2. The amount allocated to small stocks should be reduced in Regime 1 by values between $1.80 \%$ (for 48 months) and $2.76 \%$ (for 3 months) and the remaining amount should be deducted from momentum stocks. For a less risk averse investor, the optimal rebalancing amount is smaller. An investor with a relative risk aversion of 3 should allocate between $1.85 \%$ (for an investment horizon of 3 months) and $5.13 \%$ more to value stocks in Regime 1 than in Regime 2 . In Regime 2, the allocation to momentum stocks should be increased by $2.26 \%$ (for 3 months) and $4.15 \%$ (for 12 months). 

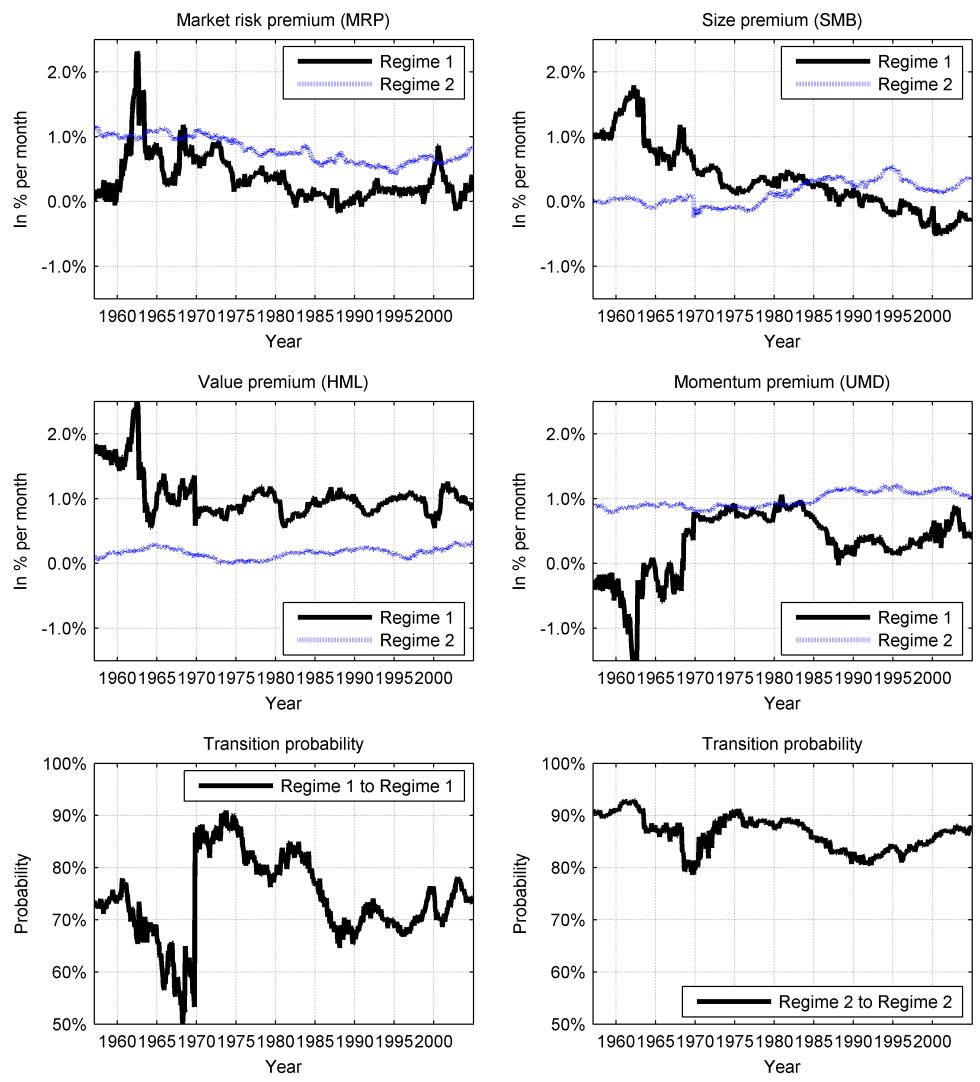

Figure 2: Estimated parameters of the regime-switching model based on a rolling window

The figure shows the estimated parameters using a rolling window of 30 years. The plots show the estimated risk premia for the four risk factors (in $\%$ per month) and the estimated transition probabilities. Regime 1 is the High-Variance Regime and Regime 2 is the Low-Variance Regime. 
Table 4: Estimated parameters for univariate regime-switching The table shows the estimated parameters for the model with univariate regime-switching. Mean returns and volatilites have been annualized. Regime 1 is characterized by high volatility and a low return of the market risk (MRP), and for momentum stocks (UMD) whereas small stocks (SMB), and value stocks (HML) show a high return. In Regime 2, volatility is rather small, and the returns for the market portfolio (MRP) and momentum stocks (UMD) are high, whereas small stocks (SMB) and value stocks (HML) stocks display a low return. Regime 1 occurs between $10.7 \%$ and $18.7 \%$ of the time and Regime 2 occurs $75 \%$ of the time. The transition probabilities show that the duration of Regime 1 is small compared to Regime 2. The persistence probabilities are between 0.71 and 0.89 for Regime 1 and between 0.97 to 0.98 for Regime $2 .{ }^{*}$ denotes a value significant on the $95 \%$ level and ${ }^{* *}$ a value significant on the $99 \%$ level. Standard errors are in parenthesis.

\begin{tabular}{rrrrr}
\hline Regime 1 & MRP & SMB & HML & UMD \\
\hline Mean & $-15.96(13.24)$ & $11.93(14.77)$ & $17.27^{*}(6.70)$ & $-0.39(10.75)$ \\
Volatility & $39.21^{* *}(3.66)$ & $28.42^{* *}(6.55)$ & $23.82^{* *}(1.86)$ & $35.62^{* *}(2.71)$ \\
\hline Regime 2 & & & \\
\hline Mean & $11.42^{* *}(1.89)$ & $1.26(1.15)$ & $3.11^{*}(1.12)$ & $10.78^{* *}(1.24)$ \\
Volatility & $13.47^{* *}(0.47)$ & $8.47^{* *}(0.56)$ & $7.57^{* *}(0.32)$ & $9.07^{* *}(0.31)$ \\
\hline State Counter & & & \\
\hline Regime 1 & $124.43(21.98)$ & $175.71(27.14)$ & $100.36(51.22)$ & $149.22(16.76)$ \\
Regime 2 & $811.57(21.98)$ & $760.29(27.14)$ & $835.64(51.22)$ & $786.78(16.76)$ \\
\hline Transition matrix & & & \\
\hline $\mathrm{P}(1,1)$ & $0.89(0.04)$ & $0.89(0.03)$ & $0.71(0.13)$ & $0.86(0.05)$ \\
$\mathrm{P}(2,2)$ & $0.98(0.01)$ & $0.98(0.01)$ & $0.97(0.01)$ & $0.97(0.01)$ \\
\hline
\end{tabular}



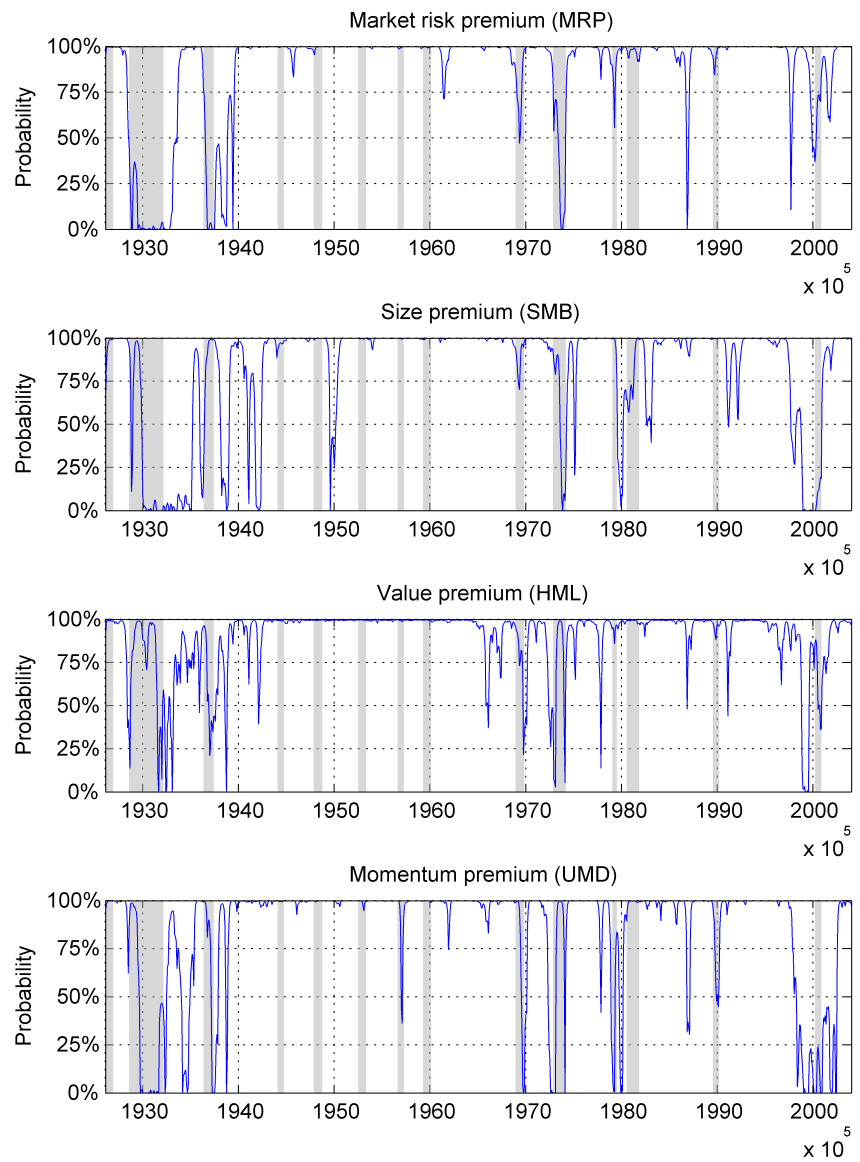

\section{Figure 3: Estimated probabilities for Regime 2 for univariate regime-switching}

The Figure shows the estimated probabilities for Regime 2 for the univariate regime-switching model. Shaded areas show NBER recessions. 

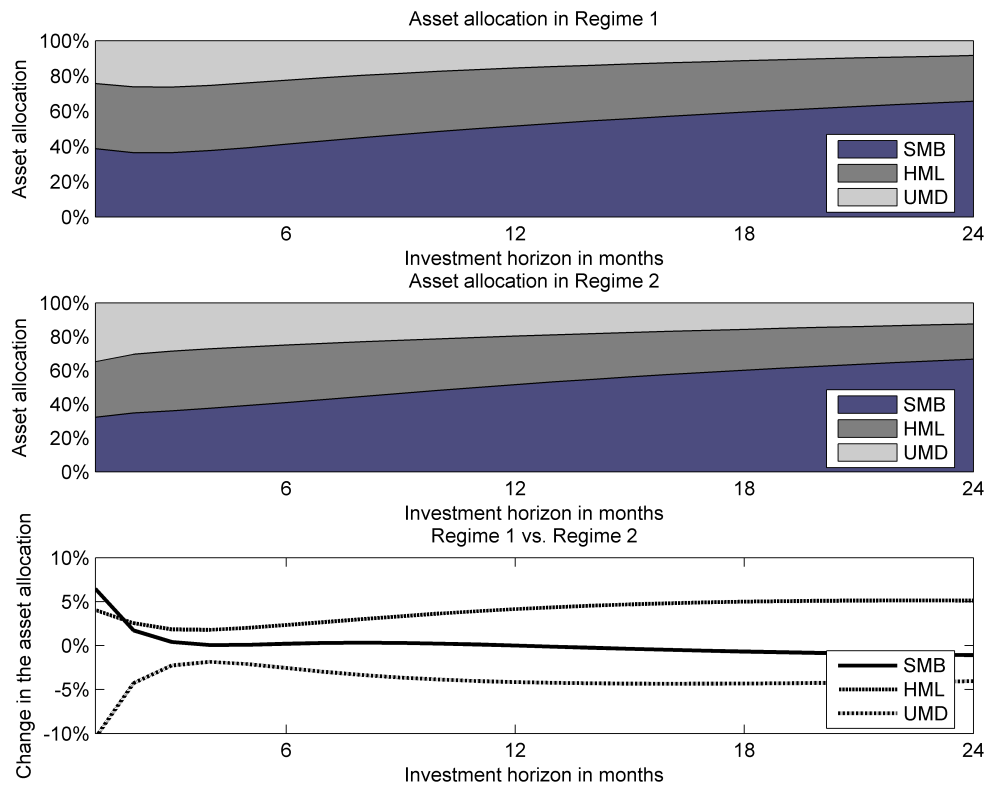

Figure 4: Asset allocation for $\gamma=3$

The figure shows in the upper and middle part the asset allocation to the style factors small stocks (SMB), value stocks (HML) and momentum stocks (UMD) for a degree of relative risk aversion of $\gamma=3$ in relation to the investment horizon conditional on the prevailing regime. In the lower part, the figure shows the changes in portfolio weights. In both settings, investors should allocate a substantial amount to small and value stocks. A comparision of the allocation in the regimes shows that in the High-Variance Regime (Regime 1), investors should allocate more to small and value stocks and less to momentum stocks. The findings for different degrees of risk aversion are qualitatively similar. Allocation to MRP is not shown because the portfolio optimization indicates that the optimal weight is zero. 


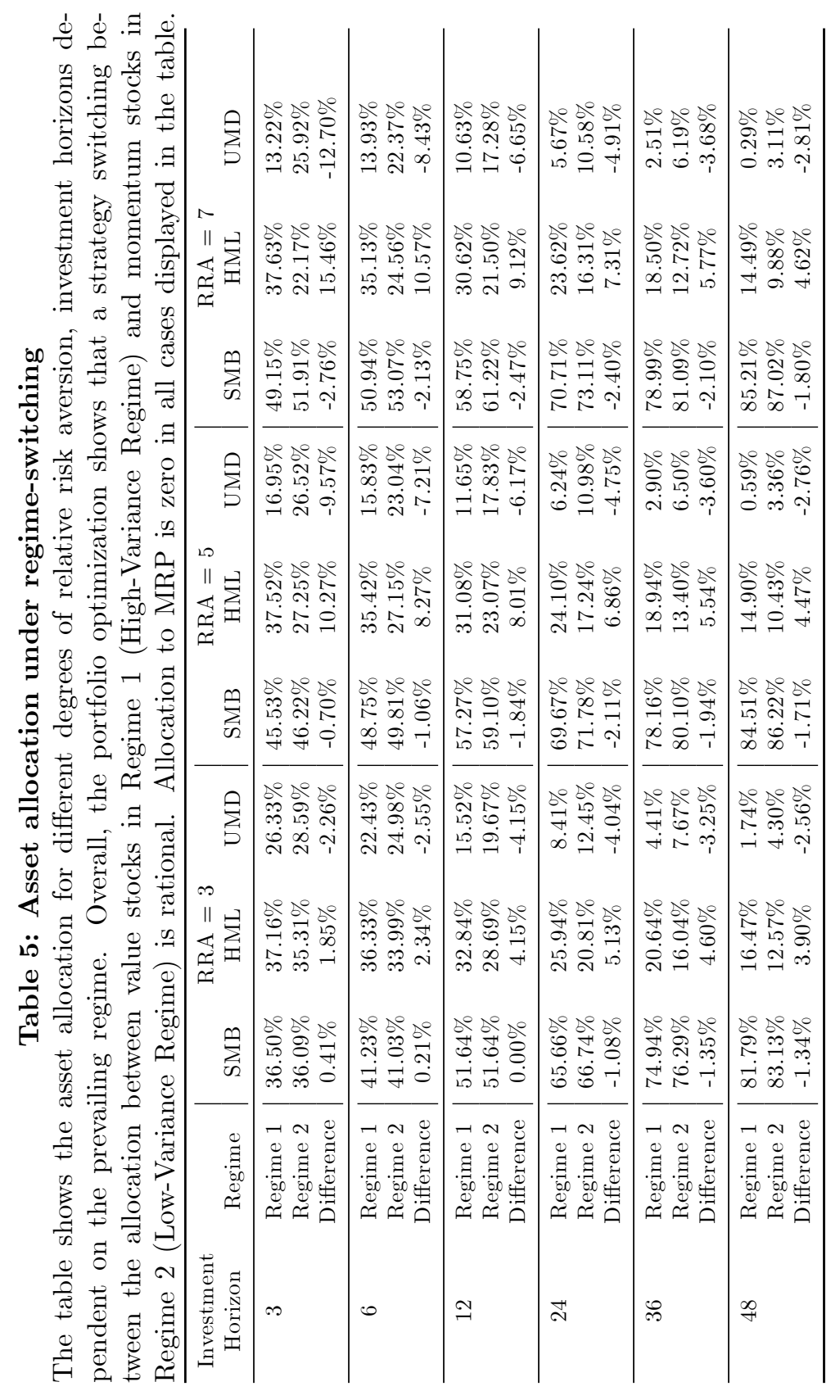


The table shows that the main results and findings are very robust with regard to different settings. Although the exact allocation changes, the results can be summarized as follows. First, the higher the risk aversion, the higher the allocation to small stocks and the lower the allocation to value and momentum stocks. Second, the longer the investment horizon, the higher the allocation to small stocks and the lower the allocation to value and momentum stocks. Third, the investor should focus on value stocks and decrease the amount allocated to small and momentum stocks in Regime 1. Consequently, the opposite result holds for Regime $2 .{ }^{1}$

The standard critique of portfolios choice (such as parameter instability and estimation risk) also apply in this case. Nonetheless, it can be concluded that value stocks should be overallocated in Regime 1 whereas momentum stocks should be overallocated in Regime 2. Our further investigations focus on the empirical performance of trading strategies following this insight.

\subsection{Tactical Asset Allocation under Regime Switching}

In this section, we test the empirical performance of the regime-switching model as a tactical asset allocation tool.

Table 6 shows the root-mean-squared error (RMSE), the correlation between forecasted and realized returns, and the intercept and slope from a regression of realized returns on forecasted returns to assess the out-ofsample performance of the regime-switching model. We compare the results of a regime-switching model with an iid model. In the iid model, the forecast for next periods returns is equal to the mean return during the sample period. The results reported in Table 6 are based on a rolling window of 30 years.

For all risk factors, the RMSE is equal or slightly higher than for the iid model. For example, the RMSE for MRP is 4.38 for both models, 3.92 for UMD in the regime-switching model and 3.91 in the iid model. Similarly, the correlation between forecasted returns and realized returns is close to 0 for the regime-switching and the iid model, but is slightly negative. Corre-

\footnotetext{
${ }^{1}$ We did not analyze the hedging demand induced by regime switching in our analysis as in Ang \& Bekaert (2002).
} 


\section{Table 6: External validity of forecasted returns}

The table shows the out-of sample performance of the regime-switching model (MRP RS, SMB RS, HML RS, and UMD RS) and a naive iid model (MRP IID, SMB IID, HML IID, UMD IID) based on a rolling window of 30 years. For the iid model, the forecast for the return of the next period is the mean return during the sample period. The table shows the root-meansquared error (RMSE), the correlation between forecasted returns and realized returns, and the intercept and slope coefficient from a regression of realized returns on forecasted returns. ${ }^{*}$ denotes significant on the $95 \%$-level.

\begin{tabular}{ccccc}
\hline & RMSE & Correlation & Intercept & Slope \\
\hline MRP RS & 4.38 & -0.03 & 0.73 & -0.35 \\
SMB RS & 3.11 & -0.02 & 0.19 & -0.24 \\
HML RS & 2.84 & -0.01 & 0.54 & -0.15 \\
UMD RS & 3.92 & -0.02 & $1.04^{*}$ & $-0.25^{*}$ \\
\hline MRP IID & 4.38 & -0.06 & $1.24^{*}$ & $-1.15^{*}$ \\
SMB IID & 3.10 & -0.06 & 0.45 & -1.63 \\
HML IID & 2.83 & $-0.08^{*}$ & $2.31^{*}$ & $-4.11^{*}$ \\
UMD IID & 3.91 & -0.04 & 1.74 & -1.15 \\
\hline
\end{tabular}

lations are smaller in absolute values for the regime-switching model than for the iid model. Overall, both models seem to have very weak, but negative predictive character. In other words, both models seem to forecast returns in the wrong direction. This finding is confirmed by the predictive regressions of realized return on forecasted returns. If forecasts are unbiased, the intercept of this regression should be 0 , the slope coefficient 1 . A comparison of the intercept for the regime-switching model and the iid model reveals that both models overestimate future returns in general. For example, the intercept for MRP is 0.73 for the regime-switching and 1.24 for the iid model. The slope coefficient indicates that the relationship between forecasted returns and realized returns is stronger in the iid model than in the regime-switching model. However, all estimated coefficients are negative. This indicates a bias in the forecasts generated by both models. Overall, for all statistical criteria, we find that the forecasting ability for the regime-switching model seems to be poor in comparison to the iid model.

Table 7 shows the empirical performance of a number of different trading strategies based on the regime-switching model. For each risk factor, we test 
a buy-and-hold strategy and strategies switching to cash in Regime 1 and Regime 2. Based on the results from the portfolio optimization, we test a trading strategy mixing value and momentum investing. For each strategy, we report the mean return, the standard deviation, and the Sharpe ratio. Using a sign test, we test for the equivalence of the median return of the buy-and-hold strategy and the switching strategy. The results displayed in Table 7 use a rolling window of 30 years. We estimate the prevailing regime at time $t$ by using a sample starting 30 years before $t$ and ending at time $t$. If the estimated probability for Regime 1 at time $t$ is higher than 0.5 , the prevailing regime is assumed to be Regime 1 and vice versa. Based on this prevailing regime, the investment decisions are taken and successive returns are computed. The sample period for the rolling analysis starts in 1957 and ends in 2004 . 


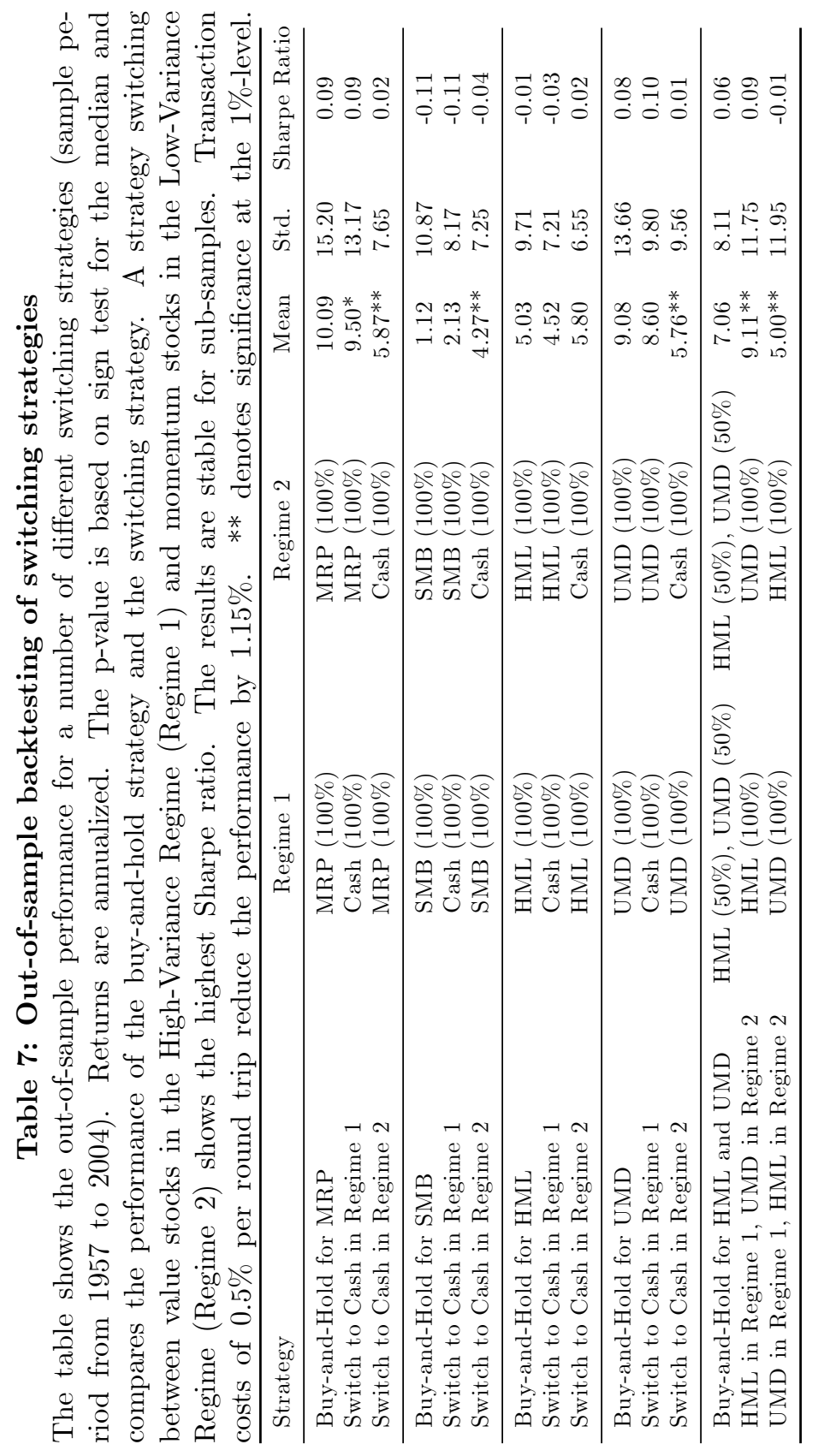


An investor holding only the market portfolio can implement a simple market-timing strategy based on the regime-switching model. If the investor switches to cash when the model signals Regime 1, the average return is reduced slightly by $0.59 \%(10.09 \%-9.50 \%)$, volatility by $2.03 \%(15.20 \%$ $13.17 \%$ ). From a Sharpe ratio perspective, both strategies are equivalent.

For the size premium, switching to cash in Regime 1 increases the return by $1.11 \%(2.23 \%-1.12 \%)$ and decreases the volatility by $2.7 \%(10.87 \%$ $8.17 \%$ ). Switching to cash in Regime 2 increases the average return by $3.15 \%$ $(4.27 \%-1.12 \%)$ and reduced volatility by $3.62 \%(10.87 \%-7.25 \%)$. Both switching strategies show a superior performance compared to the buy-andhold strategy. This finding is due to the fact that the average risk-free rate in the backtesting period was higher than the size premium.

For the value premium, a strategy switching to cash in Regime 2 increases the return by $0.76 \%(5.80 \%-5.03 \%)$ and decreases the volatility by $3.16 \%(9.71 \%-6.55 \%)$ compared to the buy-and-hold strategy. A strategy switching to cash in Regime 1 and to value stocks in Regime 2 decreases the return by $0.52 \%(5.03 \%-4.52 \%)$ compared to the buy-and-hold strategy.

Historically, a buy-and-hold momentum investor earned $9.08 \%$ with an annualized volatility of $13.66 \%$ in the backtesting period. Switching to cash in Regime 1 reduced this return slightly by $0.48 \%(9.08 \%-8.60 \%)$ and decreased the risk of the portfolio strongly by $3.86 \%(13.66 \%-9.80 \%)$. The incorrect switching strategy, i.e., switching to cash in Regime 2 , reduced the return of the portfolio substantially by $3.32 \%(9.08 \%-5.76 \%)$.

As indicated by the portfolio optimization, switching between value and momentum stocks seems to be a reasonable strategy. A pure buy-andhold strategy consisting of $50 \%$ value stocks and $50 \%$ momentum stock was inferior to a strategy switching to $100 \%$ value stocks in Regime 1 and to $100 \%$ momentum stock in Regime 2. The mean return increased from $7.06 \%$ to $9.11 \%$, the Sharpe ratio from 0.06 to 0.09 . As expected, the incorrect switching strategy, i.e., switching to value stocks in Regime 2 and to momentum stocks in Regime 1 was inferior to a simple buy-and-hold and to the correct switching strategy. A return of $5.00 \%$ for the incorrect switching strategy and a standard deviation of $11.95 \%$ lead to a Sharpe 
ratio of -0.01 .

However, the results for MRP on the one hand and for SMB, HML, and UMD on the other hand cannot be compared directly. The three style factors are calculated, as shown by Fama \& French (1993), based on longshort portfolios whereas MRP is based on a long-only portfolio. Long-short portfolios require no initial investment in contrast to long-only portfolios and therefore, depending on margin requirements, the interest rate earned on the margin account must be added to make those positions comparable.

The robustness of the results has been investigated. The results are stable across sub-periods. Also, after accounting for transaction costs, the results remain stable. In the period 1957-2004, the switching approach leads to 110 rebalancing actions in 576 months. If transaction costs of $0.5 \%$ for a full round-trip are taken into account, the performance for each switching strategy is reduced by $1.15 \%$ per year.

For the actual application of the proposed switching strategy, it is important that the long-short portfolios SMB, HML and UMD are investable. A number of problems might arise. For example, high transaction costs due to the large number of stocks might prevent actual construction of these portfolios. Moreover, the information necessary for portfolio construction might not be available at the time of construction.

As proxies for SMB and HML, exchange traded funds (ETF) can be used. For example, SMB can be replicated cost efficiently by a long position on the Russel 2000 Index measuring the performance of the 2000 smallest companies in the Russell 3000 Index and a short position in the Russell Top 200 Index. HML can be replicated with a long position in the Russell 3000 Value Index and a short position in the Russell 3000 Growth Index. Short selling of ETFs is possible, even for private investors, at low costs on US stock exchanges. For other markets, where no suitable ETFs are available, long only strategies might be an opportunity. Alternatively, statistical techniques to reduce the number of stocks for replication without significantly increasing the tracking error could be used. For the UMD portfolio, transaction costs might be a problem due to frequent rebalancing. Korajczyk \& Sadka (2004) analyze whether momentum strategies remain 
profitable after considering trading costs. They find that liquidity-weighted and value-weighted strategies remain profitable after trading costs if the fund size is less than $\$ 5$ billion. Similarly, Rey \& Schmid (2004) analyze the feasibility of momentum strategies for the Swiss stock market. They find that the limitation of the momentum portfolio to one winner stock and one loser stock surprisingly increases the performance of the momentum strategy on the Swiss stock market.

Lacking information could be a problem for HML because current information about the current book value might not be available, especially at the beginning of the year. However, this lack of information affects all stocks in a comparable way and does not necessarily induce systematic errors in portfolio construction. Since the primary construction criterion for SMB is the market capitalization, and this number is usually available, construction should not be a problem. Similarly, UMD bases on past returns and therefore, construction should be straightforward. Moreover, for all three factors, the non-synchronicity of price knowledge and trading must be taken into account.. For example, if end-of-month prices are used for portfolio construction, then the opening price in the following month can be used to assess the profitability of a trading strategy.

\section{Conclusion}

In this paper, we analyze time-varying risk premia and the implications for portfolio choice.

In the first part, we estimate a multivariate regime-switching model for the Carhart (1997) four-factor model. We find two clearly separable regimes, a High-Variance Regime and a Low Variance Regime. In the HighVariance Regime, only value stocks deliver a good performance. In the LowVariance Regime the market portfolio and momentum stocks promise high returns. The transition probabilities show that the High-Variance Regime occurs less frequently than the Low-Variance Regime. The High-Variance Regime is also less stable than the Low-Variance Regime. Moreover, we intensively validated the out-of-sample performance and robustness of the 
regime-switching model. Overall, estimated regimes and parameters are fairly stable.

In the second part, we analyze the implications of regime-switching for portfolio choice. Using a utility maximization framework, we analyze portfolio selection for an buy-and-hold investor with different degrees of relative risk aversion and different investment horizons. We find that in the HighVariance Regime, value investing seems to be a rational strategy, in the Low-Variance Regime, momentum following. An out-of-sample backtest of the switching strategy shows that tactical asset allocation based on the regime-switching model can have superior performance, but the overall forecasting ability of the regime-switching model seems to be weak compared to the iid model.

\section{References}

Ang, A. \& Bekaert, G. (2002), 'International asset allocation with regime shifts', Review of Financial Studies 15, 1137-1187.

Ang, A. \& Bekaert, G. (2004), 'How regimes affect asset allocation', Financial Analyst Journal pp. 86-99.

Arshanapalli, B., Ouville, E. D. \& Nelson, W. (2004), 'Are size, value, and momentum related to recession risk?', Journal of Investing 13, 83-87.

Badrinath, S. \& Wahal, S. (2004), 'Momentum trading by institutions', Journal of Finance 57, 2449-2478.

Banz, R. (1981), 'The relationship between return and market value of common stocks', Journal of Financial Economics 9, 3-18.

Barberis, N. \& Shleifer, A. (2003), 'Style investing', Journal of Financial Economics 68, 161-199.

Bauer, R., Haerden, R. \& Molenaar, R. (2003), 'Asset allocation in stable and unstable times', Journal of Investing 13, 72-80. 
Bekaert, G. \& Harvey, C. R. (1995), 'Time-varying world market integration', Journal of Finance 50, 403-444.

Berk, J. B. (1997), 'Does size really matter?', Financial Analysts Journal 53, $14-18$.

Box, G. E. P. (1949), 'A general distribution theory for a class of likelihood criteria', Biometrica 36, 317-346.

Carhart, M. (1997), 'On persistence in mutual fund performance', Journal of Finance 52, 57-82.

Cochrane, J. H. (1999), 'New facts in finance.', Economic Perspectives 23(3), 36-58.

Cohen, R. B., Polk, C. \& Vuolteenaho, T. (2003), 'The value spread', Journal of Finance 58, 609-641.

Congdon, P. (2003), Applied Bayesian Modelling, John Wiley \& Sons, New York.

Cooper, M. J., Gutierrez, R. C. \& Hameed, A. (2004), 'Market states and momentum', Journal of Finance 59, 1345-1365.

Doukas, J. A., Kim, C. \& Pantzalias, C. (2002), 'A test of the errorsin-expectations explanation of the value/glamour stock returns performance: Evidence from analysts forecasts', Journal of Finance 57, 2143-2165.

Evans, M. D. D. (1994), 'Expected returns, time-varying risk, and risk premia.', Journal of Finance 49(2), 655-679.

Fama, E. F. \& French, K. R. (2002), 'The equity premium', Journal of Finance 57, 637-659.

Fama, E. \& French, K. (1993), 'Common risk factors in the returns on stocks and bonds', Journal of Financial Economics 33, 3-57.

Fama, E. \& French, K. (1998), 'Value vs. growth: The international evidence', Journal of Finance 52, 1975-1999. 
Ferson, W. \& Harvey, C. (1999), 'Conditioning variables and the cross section of stock returns', Journal of Finance 54, 1325-1360.

George, T. J. \& Hwang, C.-Y. (2004), 'The 52-week high and momentum investing', Journal of Finance 59, 2145-2176.

Ghysels, E. (1998), 'On stable factor structures in the pricing of risk: Do time-varying betas help or hurt?', Journal of Finance 53, 549-574.

Graflund, A. \& Nilsson, B. (2003), 'Dynamic portfolio selection: The relevance of switching regimes and investment horizon', European Financial Management 9, 179-200.

Gray, S. F. (1996), 'Modeling the conditional distribution of interest rates as a regime-switching process', Journal of Financial Economics 42, 2762.

Griffin, J. M., Ji, X. \& Martin, J. S. (2003), 'Momentum investing and business cycle risk: Evidence from pole to pole', Journal of Finance $\mathbf{5 8}, 2515-2547$.

Grünenfelder, T. (1999), 'Style investment and interest rate cycles in switzerland', Financial Markets and Portfolio Management 13, 302317.

Guidolin, M. \& Timmermann, A. (2005), 'Economic implications of bull and bear regimes in UK stock and bond returns', Economic Journal 115, 111-143.

Hamilton, J. D. (1989), 'A new approach to the economic analysis of nonstationary time series and the business cycle', Econometrica 57, 357-384.

Hamilton, J. D. (1994), Time Series Analysis, Princeton University Press, Princeton.

Jegadeesh, N. \& Titman, S. (1993), 'Returns to buying winners and selling losers: Implications for stock market efficiency', Journal of Finance 48, 65-91. 
Jegadeesh, N. \& Titman, S. (2001), 'Profitabiliy of momentum strategies: An evaluation of alternative explanations', Journal of Finance 56, 699720.

Kao, D.-L. \& Shumaker, R. D. (1999), 'Equity style timing', Financial Analysts Journal 55, 37-48.

Kim, C.-J. \& Nelson, C. R. (1999), State-Space Models with Regime Switching, MIT Press, Cambridge, Massachusetts.

Knez, P. J. \& Ready, M. J. (1997), 'On the robustness of size and bookto-market in cross-sectional regressions', Journal of Finance 52, 13551382 .

Korajczyk, R. A. \& Sadka, R. (2004), 'Are momentum profits robust to trading costs?', Journal of Finance 59, 1039-1082.

Levis, M. \& Liodakis, M. (1999), 'The profitability of style rotation strategies in the United Kingdom', Journal of Portfolio Management pp. 114.

Liew, J. \& Vassalou, M. (2000), 'Can book-to-market, size and momentum be risk factors that predict economic growth?', Journal of Financial Economics 57, 221-245.

Lucas, A., Dijk, R. V. \& Kloek, T. (2002), 'Stock selection, style rotation, and risk', Journal of Empirical Finance 9, 1-34.

Merton, R. (1971), 'Optimum consumption and portfolio rules in a continuous-time model', Journal of Economic Theory 3, 373-413.

Moskowitz, T. J. \& Grinblatt, M. (1999), 'Do industries explain momentum?', Journal of Finance 54, 1249-1289.

Rey, D. (2000), 'Time-varying stock market correlations and correlation breakdown', Financial Markets and Portfolio Management 14, 387412. 
Rey, D. (2005), 'Market timing and model uncertainty: An explanatory study for the swiss stock market', Financial Markets and Portfolio Management 19, 239-260.

Rey, D. M. \& Schmid, M. M. (2004), 'Feasible momentum strategies', University of Basel. Working Paper.

Rosenberg, B., Reid, K. \& Lanstein, R. (1985), 'Persuasive evidence of market inefficiency', Journal of Portfolio Management 11, 9-17.

Samuelson, P. A. (1969), 'Lifetime portfolio selection by dynamic stochastic programming', Review of Economics and Statistics 51, 239-246.

Tang, G. Y. N. (1995), 'Intertemporal stability in international stock market relationsships: A revisit', Quarterly Review of Economics and Finance 35, 579-593. 